\title{
Reconsidering Peter Newmark's Theory on Literal Translation
}

\author{
Wei $\mathrm{Lu}$ \\ School of Intercultural Studies, Jiangxi Normal University, Nanchang 330022, China; \\ School of Foreign Languages, Shandong University, Ji'nan 250100, China \\ Email: Lukelw@163.com \\ Hong Fang \\ School of Intercultural Studies, Jiangxi Normal University, Nanchang 330022, China \\ Email: fh8736197@126.com
}

\begin{abstract}
Even though Translation Studies has undertaken a cultural turn and made fruitful achievements, Peter Newmark, whose theory bears a strong tint of applicability, should still be considered as one of the most important figures in the field of translation studies, especially among those who are devoted to translation practice or translation teaching. Therefore, it is not out of season here to discuss Peter Newmark and his seemingly dated theory in the present academic atmosphere of Translation Studies. Mainly based on $A$ Textbook of Translation, in which the great translation theorist strongly advocates literal translation, this paper has taken a further consideration on to what extent his theory can be applied to Chinese-English and English-Chinese translation, which would be beneficial to translation practice and translation teaching. The aim is not to put forward something new, but rather to serve as an attempt to rectify the academic extremity after the cultural turn in Translation Studies.
\end{abstract}

Index Terms - Peter Newmark, literal translation, Chinese-English and English-Chinese translation

\section{INTRODUCTION}

Ever since the late 1970s, translation theorists who, influenced by deconstructionism, has begun to switch translation studies from source-orientedness to target-orientedness. The first target-oriented paradigm was established by functionalist translation theorists represented by Reiss, Vermeer, Nord, etc., who began to "dethrone" the source text and regard it as a mere "offer of information" or the translator's "raw material" (Vermeer 1987, see Nord, 1997, p.37), thus laying emphasis on how translation is affected by such social factors as commissioner or initiator, Skopos, function, etc. while they develop functionalist approaches "with an orientation toward translator training" (Nord, 1997, p.39). Meanwhile, another target-oriented paradigm was carried out quietly in the Low Countries, which was not known to the world until the publication of an anthology of essays entitled The Manipulation of Literature: Studies in Literary Translation (Hermans, 1985), on the basis of which scholars devoted to this paradigm were dubbed "the Manipulation School" (Snell-Hornby, 1995, p.22). The aim of the Manipulation School is "to establish a new paradigm for the study of literary translation" (Hermans, 1985, p.10). What is envisaged in the new paradigm is:

a view of literature as a complex and dynamic system; a conviction that there should be a continual interplay between theoretical models and practical case studies; an approach to literary translation which is descriptive, target-oriented, functional and systemic; and an interest in the norms and constraints that govern the production and reception of translations, in the relation between translation and other types of text processing, and in the place and role of translations both within a given literature and in the interaction between literatures (ibid, p.10-11).

Thus, if the first target-oriented paradigm still bears an applied nature, the second target-oriented paradigm established by the Manipulation School has always been geared primarily towards the descriptive-explanatory goal (Toury, 1995, p.25). Whatever the paradigms, they have subverted the central position of the source text, attaching excessive importance to extralinguistic factors in translation.

Although translating can be regarded as a social or political act, to translation practitioners as well as translation teachers it has always been a primarily linguistic act. If this is the case, it is quite doubtful whether the research results of the first target-oriented paradigm established by functionalist translation theorists is really as applicable as expected if too much attention is paid to extralinguistic social factors in training translators. As to the second target-oriented paradigm established by the Manipulation School, much more doubts should be raised against it. Actually, it is the Manipulation School that makes translation studies completely break the stranglehold of prescriptivism, meanwhile forecasting the advent of the cultural turn in Translation Studies. Even though the cultural turn has made fruitful achievements in describing, explaining, and predicting translational phenomena, it is somewhat divorced too far away from pragmatism in translation theories to be regarded as of any practical use by some scholars, especially by those who are devoted to translation practice and translation teaching. Indeed, translation studies have now gone to another 
extreme by completely ignoring practical translation problems, hence increasing antagonism towards translation theory among such scholars. To call more attention to applied translation studies after the cultural turn, it has good reason to re-mention Peter Newmark and his seemingly dated translation theory, not because his theory is flawless or much more influential than any other applied translation theories, but rather because he, as one of the most important figures in the field of translation studies, has once been much more candid than other translation theorists in contending that "Translation theory's main concern is to determine appropriate translation methods...it provides a framework of principles, restricted rules and hints for translating texts and criticizing translations..."(Newmark, 1982, p.19). This paper, particularly focusing on what Peter Newmark has proposed in A Textbook of Translation, would present a reconsideration of his theory on literal translation, which is expected to be beneficial to translation practice and translation teaching. The aim is not to put forward something new, but rather to rectify the academic extremity after the cultural turn.

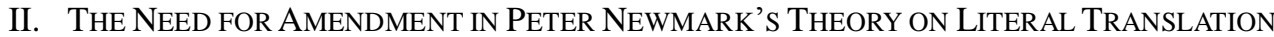

In his A Textbook of Translation, Peter Newmark (1988) has discussed more than twenty translation procedures, namely, literal translation, transference, naturalisation, etc., among which he puts special emphasis on literal translation, which occupies one chapter in that book (Chapter 7). He asserts that "literal translation is correct and must not be avoided, if it secures referential and pragmatic equivalence to the original" (ibid. p.68). To him, "literal translation is the first step in translation" (ibid. p.76) or "the most important of the procedures" (ibid. p.81), only on the following conditions can a translator retreat from literal translation: 1. A literal version is plainly inexact; 2. A vocative or informative text is badly written; 3. There are no "satisfactory" one-to-one TL equivalents for SL general words even though one is over-translating (see ibid. p.76).

Peter Newmark's view on literal translation is deeply rooted in traditional debates on the two basic translation methods, literal vs. free translation. Such debates have quite a long history both in the West and in China. In the west, the distinction between "word-for-word" (i.e. "literal") and "sense-for-sense" (i.e. "free") translation goes back to Cicero (first century B.C.) and St Jerome (fourth century A.D.), who clearly expressed the "literal" and "free" poles in translation (Munday, 2001, p.19-20). In China, the debate on "literal" vs. "free" translation might date back to as early as the Han dynasty (206 B.C. 220 A.D.) and the Three Kingdoms Period (Wei, Shu Han and Wu, which divided China from 222 A.D. 280 A.D.), during which the Sanskrit Sutras were translated into Chinese in large scales. During that period, the first Buddhist translator to be named in Chinese sources, An Shigao (? 168 A.D.), a Persian prince who renounced his claim to the royal throne of Parthia in order to serve as a Buddhist missionary monk in China, preferred slightly free translation and attracted a devoted community of followers. In Three Kingdoms Period, Zhi Qian (fl. 222 252 A.D.), a Chinese Buddhist layman of Yuezhi (an area that overlapped to at least some extent with the territory of the Kushan Empire) ancestry, had a heated debate on literal vs. free translation with other translators and wrote the first extant Chinese article on translation Preface to Fajujing. From then on, this influential translator began to prefer extremely literal translation and translated a wide range of Indian Buddhist scriptures into Chinese with such translation method.

Rather than repeat the long-standing debate on literal vs. free translation, this paper attempts to amend some of Peter Newmark's theory, which has until now been very influential in the applied translation theories. Though I quite agree with Peter Newmark's argument that "literal translation is the first step in translation", I must point out that he has emphasized literal translation so excessively that it would be even baneful to translation practice, especially to that is undertaken between Chinese and English, considering that the two languages are rather different from each other. Peter Newmark can hardly imagine the difficulties with which the translator would confront when applying his theory to Chinese-English and English-Chinese translation, for he does not know Chinese at all and has never practiced in such kind of translation. Therefore, a further consideration should be made on to what extent literal translation can be applied to Chinese-English and English-Chinese translation.

\section{SOME CONCEPTS TO Be Distinguished}

Besides literal translation, Newmark (1988, p.47) has also incidentally discussed free translation, which he surprisingly labels it "not translation at all". As mentioned above, the espousal of literal translation or free translation has dominated the discussion on methods of translation for a long time both in the West and in China. In order to avoid such meaningless disputations, which at times even go to extremes, we had better distinguish literal translation from mechanical or dead translation, and free translation from random translation.

Newmark only distinguishes literal from word-for-word and one-to-one translation:

Word-for-word translation transfers SL grammar and word order, as well as the primary meanings of all the SL words, into the translation, and it is normally effective only for brief simple neutral sentences... In one-to-one translation, a broader form of translation, each SL word has a corresponding TL word, but their primary (isolated) meanings may differ. ... Literal translation goes beyond one-to-one translation in including, say le courage, der Mut and 'courage' as literal equivalents; it is particularly applicable to languages that do not have definite and/or indefinite articles (ibid. p.69). 
In the light of Newmark, word-for-word translation and one-to-one translation should be narrower forms of literal translation, which ranges from one word to one word through group to group, collocation to collation, clause to clause, to sentence to sentence (ibid.). However, word-for-word translation, when absolutely used, may lead to mechanical or dead translation, which is not literal translation at all. Since Newmark does not mention the concept "mechanical or dead translation" in that book, here we have to draw a line of demarcation: A literal translation is a translation that follows closely both the form and intended meaning of SL, while a mechanical or dead translation is a translation that follows closely only the form of SL to the detriment of its intended meaning. The following two examples are typical of mechanical or dead translation:

1) April is a reluctant beginning of spring in Beijing.

在北京, 四月是一个春天不情愿的开端。

2)（你们俩从小在一起长大, ）可算是青梅竹马了。

(You two have been growing up together since you were little things.) You certainly have green plums and bamboo horses.

The above two examples are translated absolutely word for word, which leads to mechanical or dead translation and is plainly inexact. A plainly inexact version is not literal translation at all, but mechanical or dead translation.

Having distinguished literal translation from mechanical or dead translation, we may be more convinced that the prejudice against literal translation should be eliminated. As Wilss (1982, p.100) puts it, "In any case, literal translation seems to be rather powerful, at least in certain sorts of texts, for example LSP ${ }^{\circledR}$ texts." Although literal translation is the basic translation procedure and the starting point for all translation, no translation is completely literal, nor should that be a desirable goal. Looking back to examples 1) and 2), we may find that only free translation is possible to render them accurately:

1) 北京的四月，乍暖还寒。

2) (You two have been growing up together ever since you were a little boy and a little girl.) You certainly have had intimate childhood friendship.

The borderline between literal translation and free translation is constantly being crossed by the translator. Taking up the traditional distinction between literal and free translation, Hockett and Chao have the following to say:

"The terms 'literal' and 'free' thus do not really form a clear binary contrast. A word-by-word rendering is literal as compared with a loose translation of a whole sentence, but free as compared with morpheme-by-morpheme rendering. It may be proposed that, for any give passage, there are as many degrees of literalness and freedom of translation as there are levels of hierarchal structures in the passage".

"A common distinction is often made between literal or word-for-word translation and idiomatic or free translation. But there are more than just two degrees on the scale of literalness and idiomaticity. If we go below the level of the word, there can also be morpheme-by-morpheme translation, while if one tries to translate proverb by proverb, there is often no corresponding internal structure at all". (quoted from Wilss, 1982, p.87).

Nevertheless, the fuzziness that exists on the borderline between literal translation and free translation does not indicate that they are just the same. A literal translation follows closely both the form and intended meaning of the SL, while a free translation abandons the form of the SL, only keeping its intended meaning. At least at the lexical or sentential level, they are distinct from each other with their respective features. Sometimes the translator must translate literally because no genuine alternative to a literal translation procedure exists, sometimes he or she has to translate freely when literal translation is impossible, while at other times he or she can translate both literally and freely, which translation procedure to choose being determined by various factors. Whatever the translation method the translator chooses, he or she must at least guarantee that the translation follows exactly the intended meaning of the source text. In this sense, free translation only has limited freedom. An excessively free translation is nothing but random translation, which keeps neither the form nor the intended meaning of the source text and which the translator should be wary of falling into.

With the above notions being distinguished from each other, it has now been clear that even the notion of "literal translation" is not made clear by Newmark. Both literal translation and free translation should definitely be an exact rendition of the intended meaning of the source text; therefore, a plainly inexact version is caused by neither literal translation nor free translation, but by either mechanical translation or random translation. If we accept this point, Newmark's first above-mentioned condition on which the translator can retreat from literal translation has lost its theoretical ground.

\section{TRUTH, ACCURACY AND BEAUTY}

Newmark (1988, p. xi) considers himself somewhat of a "literalist", because he is for truth and accuracy. "Truth" and "accuracy" seem to be his criteria for a good translation. Therefore, when replying to "insidious resistances" to literal translation, he argues, "Apart from translationese (i.e. inaccurate translation) the only valid argument against what I might find an acceptable literal translation of an ordinary language unit is that you find it unnatural" (ibid. p.75). Even when considering unnaturalness, he contends that "in fact, by repeating several times to yourself a slightly 'unnatural'

\footnotetext{
${ }^{(1)}$ This is Wilss' abbreviation term for "Language for Special Purposes"
} 
unit of language, or by saying it in a soft tone of voice, you can sometimes make it sound more natural, and convince yourself it is a good translation" (ibid. p.76). Generally speaking, this argument has two defects: 1. "Truth" and "accuracy" cannot be regarded as the sole criteria for a good translation. Especially in literary translation, "beauty" should be added to the criteria. 2. If the source text is not unnatural for SL readers, it may be ridiculous to convince yourself that an unnatural translation is a good translation.

To make a convincing argument, "truth" here is defined as being factually, stylistically and culturally faithful to the source text. Newmark seems to equate "truth" only with the facts of matter and the style of the source text, therefore, he contends that the translator is entitled to correct, clarify and reorganize the facts and style of poorly written vocative and informative texts (1988, p.41, 204, and passim; 1982, p.42). In my opinion, however, the translator's job is to explain in TL what the original author has expressed in SL. Whatever the type of text he or she is translating, the translator has no right to "correct" what the original author has expressed, even when he or she finds that the facts in the text do not conform to the reality. In the case of a vocative or informative text, badly written, the translator has to translate literally to show the TL readers that the original is so, except that he or she "makes use of it" (not "translates it"!) for a certain purpose. If the translator has to faithfully keep the original, Newmark's second above-mentioned condition on which the translator can retreat from literal translation, in my opinion, also holds no water.

The translator cannot be too faithful to the source text factually, stylistically and culturally, leaving the readers to judge on their own. In most cases, literal translation serves quite well in this respect. When it comes to cultural truth, however, the translator has to take the TL readers' reception into account and use literal translation meticulously. As culture is inseparable from language, translation is always accompanied by introducing SL culture to TL. Literal translation, more often than not, can do a good job in introducing SL culture. In most cases, literally translated SL culture-specific expressions may also enrich TL if generally recognized by TL readers. For example, such Chinese expressions as “特洛伊木马(Trojan horse)”, “斯芬克司之迷(Sphinx”s riddle), “象牙塔(ivory tower)”, “鳄鱼眼泪 (crocodile tears)" are all adopted from literal translation. Free translation can never achieve such effect; sometimes it may even give TL readers false impressions of the SL culture. For instance, to translate "Beauty lies in the lover's eyes" into “情人眼里出西施” may cause the Chinese readers wonder how “西施” materializes in a text of foreign language, while a literal version “情人眼里出美人” is more appropriate.

Effective as literal translation seems to be in this respect, when the gap between two cultures is too large at some points, literal translation can only cause confusion or misunderstanding, for example:

3) He works like a dog.

Literal Translation: 他象狗一样工作。

Free Translation: 他拼命工作。

4) 他是帝国主义的走狗。

Literal Translation: He was a running dog of imperialism.

Free Translation: He was a lackey of imperialism.

As the connotations of "dog" and “狗” are quite different in the two cultures, literal translation of the above examples only causes opposite effect among TL readers. In this case, the translator has to choose free translation, converting the figurative elements of SL into the corresponding package in TL, thus neglecting the cultural truth of SL.

Another criterion, "accuracy", which requires the translator to render the source text appropriately, is the soul of translation. Under no circumstances should the translator sacrifice "accuracy", otherwise he or she will fall into mechanical or random translation. Newmark seems to try to impress the reader that only literal translation can achieve accuracy. What I want to point out is that literal translation does not necessarily indicate accuracy, though in some cases accuracy can only be achieved through literal translation, as the translation of "Beauty lies in the lover's eyes" shows. "Accuracy" is a rather complex problem, which requires the translator to give full consideration of such factors as the expression habits of TL, the readership, the aesthetic function, etc. and to use corresponding translation procedures.

\section{A. The Expression Habits of $T L$}

As to English and Chinese, the most obvious difference in their expression habits should be grammar. For instance, in English, grammatical agreement comes before semantic agreement, while in Chinese, semantic agreement comes first. Therefore, "he” in the following English sentence, if translated literally into “他”, not freely into “他们”(they), would be inappropriate:

5) The US infantryman, while requiring far too luxurious logistical support, put up a nice fight in France; he was fresh, well-fed and unscarred by battle.

Obviously, in the above sentence "infantryman" is used as a mass noun, meaning "foot soldiers collectively". Therefore, even though the third person singular pronoun "he" is used to refer to "the US infantryman" for the sake of grammatical agreement, this pronoun must be translated into the third person plural pronoun “他们”, or it would be semantically wrong in Chinese.

Another most obvious difference in expression habits between English and Chinese should be logic. The following expressions would show how different Chinese and English are in logic thinking:

6) 双杜 (literally: double bars)—parallel bars 
座钟(literally: sitting clock)—standing clock

太平门 (literally: peace door)—emergency exit

教练车 (literally: coach vehicle) - training vehicle/ student vehicle

九折 (literally: ninety percent discount)—10 percent discount

Had such kind of Chinese expressions been translated literally into English, the English reader would misunderstand the original meaning, or even get completely confused.

Difference in expression habits between English and Chinese can be manifested in such other aspects as rhetoric, word order, etc., and it is neither possible nor necessary to enumerate all of them in this single paper. However, the above two examples have sufficed to make clear this point: When TL is quite different from SL in expression habits, literal translation should be avoided, or it would cause some trouble.

\section{B. The Readership}

In real-life translation practice, it is not uncommon that a source text can be rendered differently with different readers in mind. The readership, therefore, is also an important factor that determines which translation procedure secures accuracy. The following example can make this point simply clear:

7) He had been faithful to the fourteen-year-old Vicar's daughter whom he had worshipped on his knees but had never led to the altar.

If the readers are quite familiar with the western culture, the translator has no problem in translating the italic part literally into “但他从没有把她带到圣坛前面”; however, for readers who neither know anything about nor have any interest in the western wedding custom, the translator has to translate it freely into “但他从没有同她结婚”. In such cases, we cannot judge which translation is more accurate. The different choices just correspond with the 'Skopos rule', which Nord (1997, p.29) regards as the top-ranking rule for any translation and intends to solve the eternal dilemmas of free vs. faithful (i.e. literal) translation, etc.

\section{The Aesthetic Function}

Talking about the aesthetic function, Newmark $(1988$, p.42) admits that in translation —in particular, poetry-there is often a conflict between the expressive and the aesthetic function ("truth" and "beauty") - the poles of ugly literal translation and beautiful free translation. This reminds us of the sexist quip made by early Renaissance Italian writers that "translations are like women - homely when they are faithful and unfaithful when they are lovely" (Nida, 1964, p.2). "Truth" and "beauty" seem to be incompatible, resulting respectively from literal translation and free translation.

However, putting "truth" and "beauty" to mutually repulsive poles is neither desirable nor realistic in translation practice. Even as a literalist, Newmark (1988, p.43) also points out that if the translation is "ugly" (cacophony), the purpose of the text is defeated. Therefore, "beauty", which concerns the aesthetic function of the text, is also a very important criterion for a good translation. If a literal translation is ugly, the translator is justified to use free translation, which sometimes involves in abandoning unimportant 'detail truth' (Zhang, 1987, p.194) in the source text for beauty's sake. The following is a typical example:

8) "He is seventy-six years of age," said Mr. Smallweed.

Mrs. Smallweed piped up: "Seventy-six pounds! Seventy-six thousand bags of money! Seventy-six hundred thousand million of parcels of banknotes!"

Literal Translation:

“他今年七十六岁,”斯墨尔维德先生说。

斯墨尔维德太太尖叫起来: “七十六英镑! 七万六千袋钱! 七兆六千亿包钞票!”

Free Translation:

“他今年七十六岁,”斯墨尔维德先生说。

斯墨尔维德太太尖叫起来: “七十六英镑! 七十六万袋钱！七十六万万包钞票！”

As compared with the literal version, the free one is less faithful to the source text in rendering some of the numbers, yet it depicts the old miser more vividly and we cannot say that it distorts the intended meaning. On the contrary, as far as the aesthetic function is concerned, the free version is much more accurate in rendering the source text. Thus, if a beautiful free translation secures the intended meaning, abandoning some unimportant detail truth cannot be regarded as inaccurate and unfaithful. Quote what Keats said - "Beauty is truth, truth beauty".

\section{CONCLUSION}

So far Peter Newmark's arguments on literal translation have been reconsidered further by using examples from both Chinese-English translation and English-Chinese translation. Although very much useful to translation practice and translation teaching, some of his strong advocacies of literal translation are not convincing in Chinese-English and English-Chinese translation circumstances. Though he has mentioned three conditions on which the translator may retreat from literal translation, according to the above discussion, only the third condition is totally reasonable, i.e. there are no "satisfactory" one-to-one TL equivalents for SL general words even though one is over-translating.

In addition, the translator should be refrained from literal translation under such other conditions: 1 . When the gap 
between two cultures is so large at some points that literal translation may cause confusion or misunderstanding; 2. When TL is too different from SL in some expression habits to make literal translation possible; 3 . When the translator thinks TL readers will not appreciate a literal version; 4 . When a free version is more beautiful and readable and it also does not distort the intended meaning. Whatever translation procedure the translator applies, he or she must bear in mind that it should be appropriate under a certain condition. Only with this idea in mind can Peter Newmark's theory be of much use to translation practitioners.

\section{REFERENCES}

[1] Hermans, T. (ed.) (1985). The Manipulation of Literature: Studies in Literary Translation. London \& Sydney: Croom Helm.

[2] Munday, J. (2001). Introducing Translation Studies: Theories and Applications. London \& New York: Routledge.

[3] Newmark, P. (1982). Approaches to Translation. Oxford: Pergamon Press Ltd.

[4] Newmark, P. (1988). A Textbook of Translation. Hertfordshire: Prentice Hall International (UK) Ltd.

[5] Nida, E. A. (1964). Toward a Science of Translating: With special reference to principles and procedures involved in Bible translating. Leiden: Brill.

[6] Nord, C. (1997). Translating as a Purposeful Activity: Functionalist Approaches Explained. Manchester: St. Jerome Publishing.

[7] Snell-Hornby, M. (1995). Translation Studies: An Integrated Approach (Revised Edition). Amsterdam/Philadelphia: John Benjamins Publishing Company. (First edition in 1988).

[8] Toury, G. (1995). Descriptive Translation Studies and Beyond. Amsterdam/ Philadelphia: John Benjamins Publishing Company.

[9] Wilss, W. (1982). The Science of Translation: Problems and Methods. Tübingen: Gunter Narr.

[10] Zhang, J. (1987). The Principles of Literary Translation. Zhengzhou: He'nan University Press.

Wei Lu set foot in the field of Translation Studies in 2002, when he began to pursue his master's degree in Shanghai. Ever since he was awarded master's degree for Translation Studies by Shanghai International Studies University in March, 2005, he has been a lecturer at School of Intercultural Studies, Jiangxi Normal University, Nanchang, China. He mainly teaches English-Chinese translation and his research interests lie in the fields of translation studies and intercultural communication. Presently he is a doctorial candidate at School of Foreign Languages and Literature, Shandong University, Ji'nan, China. His doctorial program is under the supervision of Dr. LI Defeng at Department of Linguistics, SOAS, University of London, United Kingdom.

Hong Fang is a professor at School of Intercultural Studies, Jiangxi Normal University, Nanchang, China. Her research interests mainly lie in the fields of second language acquisition and intercultural communication. 